\title{
Evolução dos estudos sobre a temática 'Redes' entre pesquisadores do GT7 nos ENANCIBS (2011 a 2016)
}

Alzira Karla Araújo da Silva

Doutora em Ciência da Informação (UFMG). Professora do Programa de Pós-graduação em Ciência da Informação da Universidade Federal da Paraíba (PPGCI UFPB)

Rafael Silva da Câmara

Doutorando em Ciência da Informação (PPGCI UFPB)

Kelly Cristiane Queiroz Barros

Doutoranda em Ciência da Informação (PPGCI UFPB)

http://dx.doi.org/10.1590/1981-5344/3080

Pesquisa exploratória e quali-quantitativa, apoiada em pesquisa bibliográfica, que objetiva caracterizar a evolução da pesquisa científica sobre o tema "Redes" no Grupo de Trabalho 7 (GT7), entre os anos de 2011 a 2016, da Associação Nacional de Pesquisa e PósGraduação em Ciência da Informação (ANCIB). Discute as abordagens e teorias de Redes Sociais, como os conceitos, as tipologias e metodologias. Apresenta e discute as redes de autores que publicaram sobre "Redes" no Encontro Nacional de Pesquisa em Ciência da Informação (ENANCIB), durante o período e dentro do GT analisado. Caracteriza os pesquisadores quanto a formação acadêmica. Apresenta e discute a colaboração entre instituições. Analisa os assuntos mais abordados nas publicações. Diante dos dados quantitativos, observamos presença relevante da temática dentro do GT7, receptividade da temática em instituições de quase todo o território brasileiro, a existência de conexões com instituições estrangeiras, forte relação institucional entre os atores constituindo redes de orientação, variedade de formações acadêmicas, mas com predominância de autores com formação em CI ou áreas irmãs e ocorrência significativa de redes de coautoria nos estudos de redes. 
Palavras-chave: Redes Sociais; Comunicação científica; Análise de Redes Sociais; Colaboração científica; Coautores.

\section{Evolution of studies on the 'Networks' theme between researchers of the WG7 in the ENANCIBS (2011 to 2016)}

Exploratory and qualitative-quantitative research, supported by a bibliographical research, which aims to characterize the evolution of scientific research on the theme "Networks" in Working Group 7 (WG7), between the years 2011 to 2016, of the National Research Association And Post-Graduation in Information Science (ANCIB). It discusses the approaches and theories of Social Networks, such as concepts, typologies and methodologies. It presents and discusses the networks of authors that published on "Networks" in the National Meeting of Research in Information Science (ENANCIB), during the period and within the WG analyzed. It characterizes the researchers regarding the academic formation. Presents and discusses collaboration between institutions. It analyzes the issues most addressed in the publications. In view of the quantitative data, we observed the relevance of the topic within WG7, the receptivity of the topic in institutions of almost the entire Brazilian territory, the existence of connections with foreign institutions, a strong institutional relationship among the actors constituting orientation networks, a variety of academic backgrounds, But with predominance of authors with formation in CI or sister areas and significant occurrence of co-authorship networks in network studies.

Keywords: Social Networks; Scientific communication; Analysis of Social Networks; Scientific collaboration; Coauthors.

Recebido em 22.02.2017 Aceito em 05.10.2017

\section{Introdução}

No âmbito acadêmico e científico, compreender como ocorre o crescimento e a institucionalização de disciplinas ou campos do saber são necessidades constantes. A consolidação de temas de pesquisa em 
determinadas áreas do conhecimento acontece à medida em que os pesquisadores realizam seus estudos e os divulgam para a comunidade. Por muitas vezes, este processo é possível graças à colaboração e trabalho em conjunto entre pesquisadores, trabalhando como coautores com interesses em comum.

Deste modo, se faz pertinente não apenas reconhecer a existência de redes sociais na comunidade acadêmica e científica, mas também saber quais são estas redes e a própria relevância de estudos que envolvam a temática das redes sociais e, em particular, na área da Ciência da Informação (CI), cujas pesquisas sobre esse tema têm se mostrado relevantes recentemente.

Assim, esta pesquisa tem como objetivo geral caracterizar a evolução da produção científica do tema "Redes" e afins no Grupo de Trabalho 7 (GT7), da Associação Nacional de Pesquisa e Pós-Graduação em Ciência da Informação (ANCIB), cujos trabalhos abordam a Produção e Comunicação da Informação em Ciência, Tecnologia \& Inovação. Para alcançar tal objetivo, realizou-se um levantamento das pesquisas sobre o tema "redes" nos Anais dos Encontros Nacionais de Pesquisa em Ciência da Informação (ENANCIB), ocorridos entre os anos de 2011 a 2016.

$\mathrm{Na}$ primeira parte deste artigo, discutem-se as abordagens e teorias que guiaram a análise, destacando as tipologias possíveis de redes sociais, os conceitos mais utilizados, a terminologia e a metodologia de Análise de Redes Sociais (ARS). Na segunda parte, avalia-se a relevância da temática "redes" no GT7 por meio de comparação entre o número de trabalhos selecionados e apresentados neste GT e o número total de trabalhos apresentados nestes 6 (seis) anos de diálogo entre os pares. A seguir, caracterizam-se os pesquisadores em Ciência da Informação que submeteram artigos ao ENANCIB, destacando os vínculos institucionais e as instituições dos atores nestas redes. Por fim, destacam-se os temas mais abordados nos trabalhos escolhidos.

Define-se esta pesquisa como quanti-qualitativa, exploratória, baseada em pesquisa bibliográfica. Realizou-se a coleta de dados nos Anais do ENANCIB, disponíveis online ou DVDs, realizando a leitura do sumário com o objetivo de identificar os artigos que explicitamente se denominavam "estudo de redes". A seguir, os textos completos foram acessados para a identificação de títulos, palavras-chave, autoria e vinculação institucional. A formação acadêmica de autores foi pesquisa na base Plataforma Lattes. Todos os dados foram sistematizados em planilhas Excel e a representação gráfica das redes foi realizada com o software UCINET.

\section{Terminologia em estudos de redes}

Segundo Martinho (2003, p. 15), "o desenho da rede não é suficiente para explicá-la ou caracterizá-la como um sistema com propriedades e um modo de um funcionamento específicos [...] se bastasse identificarmos a existência de ligações entre vários elementos, tudo seria efetivamente rede". Entretanto, "o conjunto de nós-e-linhas da 
rede [elementos básicos e que definem o que é uma estrutura em rede] produz organização; é, na verdade, uma forma de organização" (MARTINHO, 2003, p. 16). Uma "rede" em CI é uma comunidade científica, uma forma de organização do trabalho científico e representação dos processos informacionais.

O desenho de redes sociais faz parte de ações de visualização de informações que tem como objetivo facilitar a assimilação, o entendimento da informação explícita e auxilia na transferência do conhecimento ao traduzir dados em mensagens visíveis (PINTO et al., 2009). Esta é um dos objetivos da cienciografia ou gráfica das redes sociais, área que aborda a representação gráfica de redes sociais por meio de softwares tendo por base algoritmos complexos, e seu resultado são cienciogramas, também chamado grafos pela Teoria dos Grafos, onde são representadas as micros e macros relações que ocorrem em uma determinada comunidade. Nesse estudo, a comunidade de pesquisadores em Ciência da Informação que se agregam no Grupo de Trabalho 7 dos ENANCIBs.

Um dos princípios definidos pela cienciografia, é a possibilidade de acompanhamento do desenvolvimento evolutivo das redes em determinados intervalos de tempo, o que permite contextualizar a importância da temática "redes" nas 6 (seis) edições dos ENANCIBs escolhidos para o desenvolvimento desta pesquisa. Corrobora-se com Martinho (2003, p. 23), quando afirma que "O resultado desse desenho é um retrato momentâneo de uma pequeníssima parte de sua rede de relacionamentos".

A partir deste ponto de vista, trabalhou-se com a abordagem ampla da Análise de Redes Sociais (ARS), entendida como "uma aplicação funcional dos relacionamentos existentes em um grupo ou comunidade, seja científica ou de um entorno extremamente social" (PINTO et al., 2009, p. 292).

Discutindo a ARS como metodologia, Marteleto (2001, p. 72-74) destaca que esta se diferença pela "valorização dos elos informais e das relações, em detrimento das estruturas hierárquicas"; "a unidade de análise não são os atributos individuais (classe, sexo, idade, gênero), mas o conjunto de relações que os indivíduos estabelecem através das suas interações uns com os outros"; "não é um fim em si mesmo. Ela é o meio para realizar uma análise estrutural cujo objetivo é mostrar em que a rede é explicativa dos fenômenos analisados"; "não supõem necessariamente um centro hierárquico e uma organização vertical, sendo definidas pela multiplicidade quantitativa e qualitativa dos elos entre os seus diferentes membros, orientada por uma lógica associativa".

Martinho (2003) destaca outras características das redes sociais: possui capacidade de auto-organização; a circulação da informação ocorre de forma não linear, se espalha em todas as direções; a horizontalidade como princípio organizacional; as linhas ou conexões são mais importantes que os pontos ou atores; as conexões geram organicidade; são sistemas abertos em constante relacionamento com o meio; sua arquitetura é plástica pois se reorganiza quando alguns nós deixam de 
existir; a dinâmica de expansão é também não linear, pois "Cada ponto (pessoa), ao estabelecer uma conexão, amplia os limites da rede. Ao fazêlo, permite o estabelecimento de novas conexões com outros pontos (mais pessoas), que, com suas próprias conexões, vão empurrando os limites da rede para mais longe à medida que o fenômeno transcorre" (MARTINHO, 2003, p. 25); não há um centro, há diversos centros, portanto, redes são sistemas descentrados por definição e se não há centro não há periferia; são multidimensionais, pois várias redes funcionam simultaneamente e umas podem se conectar às outras (desdobram-se, misturam-se); são invisíveis ou tácitas que só aparecem quando são solicitadas ou acionadas; se há normas, regras, regulamentos, cargos estes são resultado de pactos e do consenso estabelecidos pelos atores.

A terminologia sobre redes sociais adotada para este trabalho é melhor visualizada no quadro 1.

Quadro 1 - Terminologia da área de pesquisa em Redes Sociais.

\begin{tabular}{|c|c|}
\hline CONCEITO & DEFINIÇÃO \\
\hline Atores / pontos & $\begin{array}{l}\text { Pessoas, organizações, equipamentos, locais, instituições etc. } \\
\text { número de pontos de uma rede não tem limites. }\end{array}$ \\
\hline Atores pontes / pontes & Fazem a conexão entre duas redes. \\
\hline Centralidade de grau & $\begin{array}{l}\text { Condição em que um ator tem o maior número de conexões } \\
\text { (ligações com outros atores). }\end{array}$ \\
\hline Centralidade de intermediação & $\begin{array}{l}\text { Condição em que um ator é ponte para maior número de outros } \\
\text { atores. }\end{array}$ \\
\hline Centralidade de proximidade & $\begin{array}{l}\text { Condição em que um ator é mais próximo de outro em } \\
\text { decorrência do menor número de ligação que os separa. }\end{array}$ \\
\hline Clique / Cluster & $\begin{array}{l}\text { "[...] grupo de atores que mantêm relações mais estreitas entre si } \\
\text { do que com outros atores que não fazem parte do grupo" } \\
\text { (MARTELETO; TOMAÉL, 2005, p. 93). }\end{array}$ \\
\hline Comunidade virtual de prática & $\begin{array}{l}\text { "[...] reúne membros por interesses comuns e pelos mesmos } \\
\text { problemas. Mas, apesar da não presença (física), congrega } \\
\text { elementos humanos de uma interação 'normal', como ideias, } \\
\text { conflitos, apoio, amizades etc." (SILVA et al., 2014, p. 228). }\end{array}$ \\
\hline Conectividade & $\begin{array}{l}\text { Capacidade de produzir conexões entre atores. O limite da } \\
\text { conectividade é atingido quando todos os atores mantêm ligação } \\
\text { com todos os demais. }\end{array}$ \\
\hline Densidade & $\begin{array}{l}\text { Conceito ligado a quantidade de linhas de uma rede, ou seja, } \\
\text { maior a quantidade de linhas (conexões), mais densa a rede. } \\
\text { Uma rede com o mesmo número de atores pode ser mais ou } \\
\text { menos densa dependendo do número de ligação existe entre } \\
\text { esses atores. Quanto mais densa, mais compacta, integrada, } \\
\text { coesa e orgânica a rede. }\end{array}$ \\
\hline Díade / tríade & Relação formada por dois ou três atores, respectivamente. \\
\hline Laços ausentes & Ator isolado, sem conexões com outros atores. \\
\hline
\end{tabular}


Laços fortes

Relação de vínculos estreitos, mais frequentes, onde há maior intimidade, intensidade emocional, os atores se veem com mais frequência, maior reciprocidade, maior variedade de relações, as redes tendem a se fecharem sobre si mesmas, é menor o fluxo de informações.

Laços fracos

Relação com vínculos menos estreitos, os atores se encontram ocasionalmente, são mais abertas ao exterior, maior o fluxo de informações pois tem contato com maior número de fontes de informação e são considerados nossas pontes para 0 mundo exterior.

Linearidade

Quando a relação tem um direcionamento e sentido, por isso se diz que as redes são não-lineares, há reciprocidade, podem ocorrer em qualquer direção ou sentido.

Linhas/arestas/ ligações/laços

As relações entre os atores, a conexão formada por dois pontos

Rede colaborativa

"Composta por indivíduos que interagem dentro de um contexto específico que formam nós de informação através da colaboração dos participantes" (BASSETO, 2013, p. 32).

\begin{tabular}{l|l}
\hline Redes formais & $\begin{array}{l}\text { Onde o fluxo de informações ocorre através de canais e } \\
\text { processos estabelecidos pela organização. }\end{array}$ \\
\hline Redes informais & $\begin{array}{l}\text { Onde o fluxo de informação ocorre através das relações sociais } \\
\text { e de forma espontânea. Há líderes naturais que movimentam a } \\
\text { rede pois são mais carismáticos, extrovertidos, referência ética e } \\
\text { profissional ou respeitados pelo conhecimento que possuem. }\end{array}$ \\
\hline Redes interorganizacionais & As relações ocorrem entre organizações independentes. \\
\hline Redes intraorganizacionais & $\begin{array}{l}\text { As relações ocorrem entre pessoas, setores, processos } \\
\text { produtivos dentro de uma organização. }\end{array}$ \\
\hline Transitividade & $\begin{array}{l}\text { Fenômeno que ocorre quando uma conexão cria uma ponte } \\
\text { entre várias redes e a possibilidade de surgimento de novas } \\
\text { conexões e redes. }\end{array}$ \\
\hline
\end{tabular}

Fonte: MARTINHO (2003); SILVA et al. (2014); BASSETTO (2013); LARA; LIMA (2009); MARTELETO; TOMAÉL (2005).

É significativa a presença do tema na literatura da CI, particularmente após o ano 2000, mostrando que a CI tem se preocupado com problemas vivenciados no presente, como a questão da disseminação de redes sociais digitais, busca novas metodologias, realiza apropriações de conceitos que se tornam operatórios e eficazes na compreensão da realidade social/informacional. Essa característica adaptativa da área vem de encontro a uma tradição de estudos de coautoria e de colaboração e comunicação científica ao longo do tempo, perspectiva que sutilmente vamos delinear.

\section{A pesquisa sobre a temática redes entre os pesquisadores em Ciência da Informação}

De acordo com o website da Associação Nacional de Pesquisa e PósGraduação em Ciência da Informação (ANCIB, 2016) as suas atividades 
[...] estruturam-se em duas frentes: os Programas de PósGraduação stricto sensu, que são representados pelos seus coordenadores, e o Encontro Nacional de Pesquisa da Ancib (Enancib), fórum de debates e reflexões que reúne pesquisadores interessados em temas especializados da Ciência da Informação, organizados em Grupos de Trabalho.

A ANCIB presenta, na atualidade, 11 Grupos de Trabalho (GTs), entre eles, o GT7 tem como finalidade a comunicação de pesquisas e diálogo sobre os seguintes temas:

Estudos teóricos, aplicados e metodológicos sobre a produção, comunicação e uso da informação em Ciência, Tecnologia e Inovação. Inclui pesquisas relacionadas aos processos de comunicação, divulgação, análise e formulação de indicadores para planejamento, avaliação e gestão em CT\&I. (ANCIB, 2016)

De acordo com os anais consultados, destacam-se as seguintes palavras-chave que caracterizam este GT: 1) Medição; 2) mapeamento; 3) diagnóstico da informação; 4) avaliação da informação nos processos de produção; 5) armazenamento; 6) comunicação; 7) uso; 8) ciência; 9) tecnologia; 10) inovação; 11) métodos e técnicas; 12) bibliometria; 13) cientometria; 14) informetria; 15) webometria; 16) análise de rede; 17) indicadores em CT\&I.

Sua criação ocorreu no ano de 2005. Entre os anos de 1994 e 2006, os temas que fizeram parte desse GT eram discutidos no GT5 e GT 6 e abordavam os temas: Produção científica/Literatura cinzenta; Comunicação científica; Comunicação e produção científica/Literatura cinzenta; Informação para diagnóstico, mapeamento e avaliação (ANCIB, 2016).

Como se pode observar no gráfico 1 , os temas relativos a redes descritas nos títulos dos artigos apresentam a seguinte distribuição: 2 ocorrências nos Anais do $12^{\circ}$ ENANCIB (2011); 1 ocorrência no $13^{\circ}$ (2012); 4 ocorrências no $14^{\circ}$ (2013); 5 ocorrências no $15^{\circ}$ (2014); 3 ocorrências no $16^{\circ}$ (2015) e, por fim, 3 ocorrências no 170 (2016). Enfatiza-se que, neste momento, foram buscados apenas trabalhos que descreviam em seus títulos palavras relacionadas com estudo de redes (rede de coautoria, rede de colaboração, redes sociais, teoria Ator-Rede, Análise de redes sociais etc.).

Gráfico 1 - Relação entre número total de artigos publicados no GT7 e o número de trabalhos sobre a temática "Redes" (2011 a 2016)

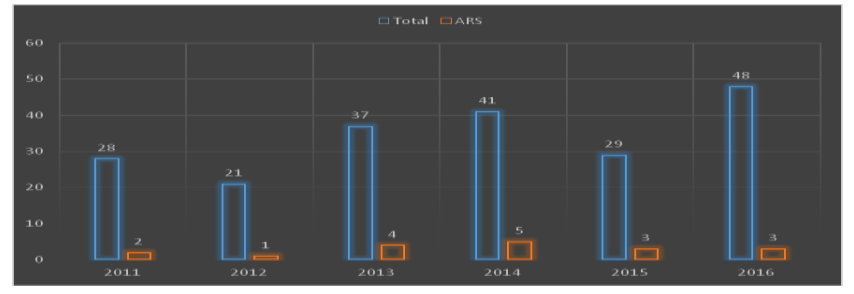

Fonte: Os autores (2016).

O Gráfico 1 é um indicativo da importância do tema "redes" entre as pesquisas apresentadas no GT7 dos ENANCIBs. A coluna azul representa o 
total de trabalhos apresentados e publicados nos Anais dos ENANCIBs, a coluna laranja, o número de trabalhos sobre Redes Sociais apresentados nos mesmos eventos.

Totaliza 204 trabalhos publicados nos Anais do ENANCIB referentes ao GT7 no período escolhido, destes, 18 fizeram referência à temática "redes" em seus títulos, número que representa $8,82 \%$ dos artigos deste GT. Diante do amplo universo de temáticas agrupadas neste GT, como observado acima (17 temas), consideramos esse número relevante e um indício da representatividade do tema.

\section{Os atores e as redes de coautoria e colaboração}

Considera-se atores neste artigo, os pesquisadores e as instituições às quais esses pesquisadores estão vinculados. A análise foi iniciada pela caracterização geral da titulação dos autores identificados.

Gráfico 2 - Titulação dos autores nos artigos do GT7 (2011 a 2016)

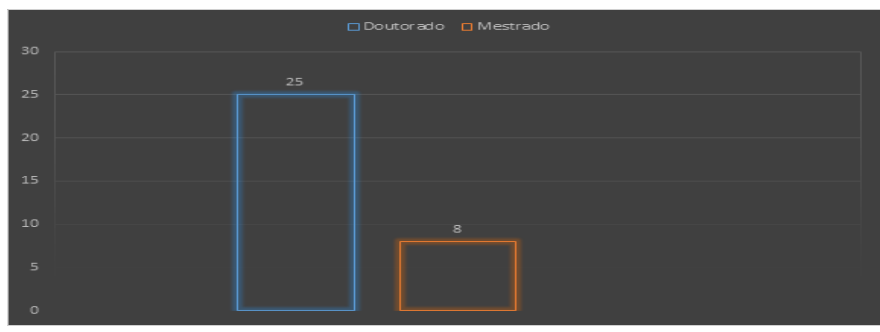

Fonte: Os autores (2016).

A identificação da titulação foi realizada por meio da busca dos currículos dos autores na Plataforma Lattes. No total, a predominância de autores com o título de Doutor verificada no gráfico acima não é relevante já que é uma exigência a titulação de Doutor na maior parte dos casos de submissão de trabalhos ao ENANCIB.

O levantamento indicou 34 autores, porém, não foi possível encontrar o currículo na Plataforma Lattes de um dos autores, consequentemente, o registro da sua titulação não foi tabulado no gráfico. Ainda assim, no levantamento dos trabalhos publicados nos Anais do ENANCIB foi possível ver que o autor possui vínculo institucional com a Universidade Federal do ABC.

Realizando a correlação entre formação acadêmica e estudo de redes sociais, observa-se uma presença relevante de pesquisadores provenientes das seguintes áreas: 
Tabela 1 - Nível de formação acadêmica

\begin{tabular}{|c|c|c|}
\hline FORMAÇÃO & CURSO & OCORRÊNCIAS \\
\hline \multirow{5}{*}{ GRADUAÇÃO } & Biblioteconomia ou Biblioteconomia e Documentação & 17 \\
\hline & Engenharia elétrica & 7 \\
\hline & $\begin{array}{l}\text { Ciências Biológicas; Engenharia de Sistemas; Gestão da } \\
\text { informação; Psicologia }\end{array}$ & 3 \\
\hline & Matemática; Pedagogia; Turismo & 2 \\
\hline & $\begin{array}{l}\text { Arquivologia; Ciências Econômicas; Comunicação Social; } \\
\text { Engenharia civil; Engenharia de Materiais; Filosofia; } \\
\text { Letras; Processamento de dados; Química; Relações } \\
\text { Públicas }\end{array}$ & 1 \\
\hline \multirow{6}{*}{ MESTRADO } & Ciência da Informação & 11 \\
\hline & Ciências da Computação & 6 \\
\hline & MBA ou Administração de empresas & 4 \\
\hline & Biblioteconomia; Educação & 3 \\
\hline & Ciências da Comunicação; Engenharia elétrica & 2 \\
\hline & $\begin{array}{l}\text { Ciência e Engenharia de materiais; Ciência, Tecnologia e } \\
\text { Sociedade; Ciências biológicas; Economia e Gestão da } \\
\text { Inovação; Economics and Management of Science and } \\
\text { Technology; Gestão de unidades de informação; } \\
\text { Information Stratégique Et Critique Veille Technol; } \\
\text { Psicologia; Sciences de l'Information et de la } \\
\text { Communication; Sociologia política. }\end{array}$ & 1 \\
\hline \multirow{6}{*}{ DOUTORADO } & Ciência da Informação & 12 \\
\hline & Ciências da Computação & 6 \\
\hline & Comunicação ou Ciências da Comunicação & 4 \\
\hline & Educação & 3 \\
\hline & Administração de empresas & 2 \\
\hline & $\begin{array}{l}\text { Avaliação de Tecnologia; Ciência da Informação e } \\
\text { Comunicação; Ciência e Engenharia de materiais; } \\
\text { Ciências documentais; Economics ou Ciências } \\
\text { econômicas; Informação e comunicação em plataformas } \\
\text { digitais; Information Stratégique Et Critique Veille Technol; } \\
\text { Interdisciplinar em Ciências Humanas; Psicologia; } \\
\text { Sociologia política }\end{array}$ & 1 \\
\hline
\end{tabular}

Fonte: Os autores (2016).

A tabela 1 mostra duas situações: o estudo de "redes" está consolidado na área da Ciência da Informação, pois houve predominância de autores com formação nesta área; há significativa presença de pesquisadores das ciências exatas (engenharias) e ciência da computação 
entre os pesquisadores da temática; como é inerente a CI, é marcante a característica interdisciplinar dessas redes, portanto, podemos olhar para elas também como

[...] redes de pesquisa científica, as redes de pesquisa científica colaborativa e as redes de pesquisa colaborativa interdisciplinar. Segundo o autor, essas redes de pesquisa têm como principais objetivos "a pesquisa, a educação e o desenvolvimento tecnológico corporativo, a colaboração externa e as atividades interdisciplinares", ocorrem de variadas formas e têm sido objeto de estudo para diversos pesquisadores. (SILVA, 2014, p. 32).

Outra questão pontual é a presença de pesquisadores com formação em ciências biológicas, fato que reflete a presença do modelo de pensamento sistêmico e dos estudos sobre redes na área da ecologia e matemática.

Ficou evidente pela relação entre os autores a existência dos laços originados da orientação acadêmica em todos os artigos analisados, ou seja, relação entre orientador e orientando, também vista como "rede de orientação" que é entendida por Balancieri (2004, p. 91) como: "Este tipo de rede diz respeito às relações de orientação (entre orientadores, entre orientados e entre orientador- orientado). De acordo com Hagstrom (1965), ocorre relação de orientação entre professores e estudantes, mesmo quando não há uma relação formal."

Essa relação pode ser interpretada como inerente à dinâmica das redes onde cada ponto da rede carrega consigo as suas conexões, cada pesquisador, no contexto de ensino e pesquisa acadêmica, trás para suas redes seus orientandos e orientandas, alimentando assim, uma rede mais ampla. Observando esta relação, vemos a caracterização de rede formalmente organizada, pois há um vínculo institucional entre pesquisador/professor e aprendiz/estudante. Por outro ponto de vista, quando essas relações se estendem para outras instituições ou para a comunidade científica, entendida como uma rede de atores que produzem conhecimento científico, haverá uma rede informalmente organizada, pois "são fruto de relações pessoais e de amizade, familiares ou formação profissional, vínculos de trabalho, afinidade política e incontáveis relações pulverizadas, assim como conhecidos e companheiros ou mesmo inimigos" (SILVA, 2014, p. 31).

Também foram analisadas as coautorias constituídas nos trabalhos do GT7. A rede de coautoria é considerada parte das redes de colaboração na CI e a constituição de Grupos de Trabalho em associações profissionais e científicas demonstra a existência de redes colaborativas. Por esse ponto de vista, a ANCIB é a maior rede colaborativa que agrega pesquisadores em Ciência da Informação do Brasil.

Dentro desse contexto específico e no contexto mais amplo do desenvolvimento da ciência atual, a comunicação científica vem ocorrendo em grande parte em coautoria. Segundo Silva et al. (2006, p. 184), diversos estudos baseados em ARS evidenciam "o crescimento relativo do número de artigos produzidos em coautoria, assim como no número de 
autores por artigo, frutos da crescente interdisciplinaridade das áreas, com impactos significativos sobre as redes de cooperação".

Gráfico 3 - Publicações em coautoria nos artigos sobre "Redes" do GT7 (2011 a 2016)

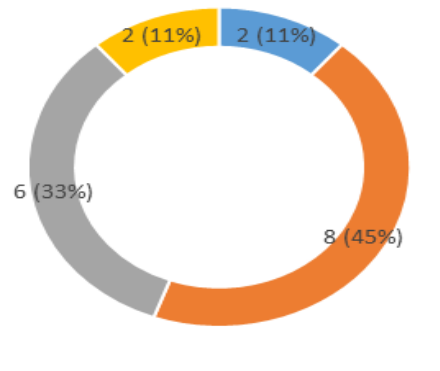

Fonte: Os autores (2016).

A partir da correlação entre autorias e ARS, observa-se que os dados coletados para esta pesquisa indicam que ocorreu autoria individual em apenas dois artigos, portanto, em dois casos se vê ocorrência de "laços ausentes". Prevaleceu a parceria entre dois autores ou a formação de díades, com $45 \%$ do total de artigos. Nesta pesquisa, as tríades correspondem a apenas $11 \%$ do número total. Artigos com mais de três autores correspondem, também, a $11 \%$ do total. A delimitação desses dados e a visualização das redes de pesquisadores do GT7 permite observar os laços fortes, fracos e ausentes (Figura 1).

Figura 1 - Rede de colaboração entre autores nos artigos sobre "Redes" publicados no GT7 (2011 a 2016)

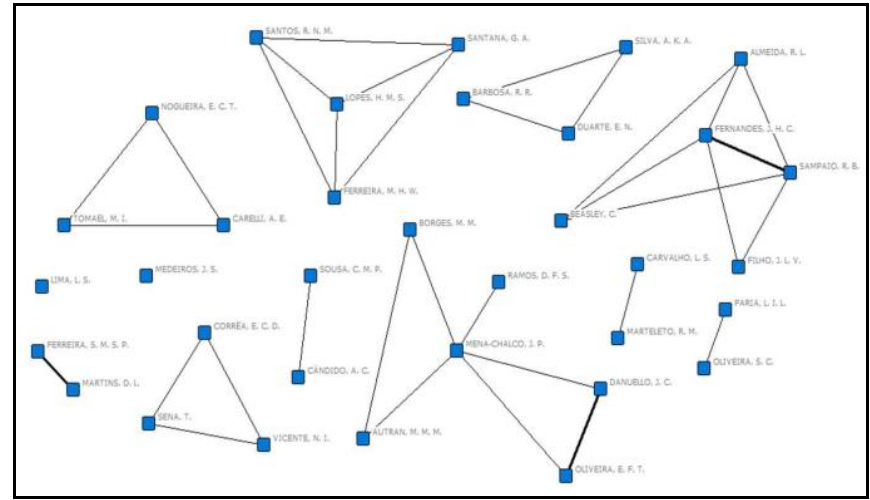

Fonte: Os autores (2016).

No gráfico acima, observa-se que os traços levemente mais fortes (arestas mais grossas) demonstram que determinados autores tiveram mais de um artigo publicado em coautoria sobre o tema e formam laços mais fortes, no caso, as díades: Ferreira e Martins; Danuello e Oliveira; e Fernandes e Sampaio. Estas três díades apresentam duas publicações em coautoria e todos os demais autores apresentam uma publicação. 
Diante da identificação dos 34 autores que publicaram sobre "Redes" no GT7 e utilizando a fórmula para o cálculo da densidade de uma rede chega-se à conclusão de que essa é uma rede pouco densa:

Figura 2 - Cálculo de densidade da rede de colaboração entre autores nos artigos sobre "Redes" publicados no GT7 (2011 a 2016)

$$
D=\underline{\mathrm{p} \times(\mathrm{p}-1)}=\frac{34 \times(34-1)}{2}=561 \text { ligações possíveis }
$$

Número total de ligações: 31

Fonte: Os autores (2016).

Segundo Martinho (2003, p. 8), "A ligação à distância é o fundamento de tal noção, primária, de rede". A partir dessa afirmação, observam-se os vínculos institucionais dos pesquisados em CI e sua dispersão geográfica. Tiveram representatividade de 16 instituições de ensino superior e de pesquisa brasileiras, sediadas em quatro regiões geográficas (Centro-oeste, Nordeste, Sudeste e Sul), e duas instituições estrangeiras, a Universidade de Coimbra e o Instituto Universitário de Lisboa (ISCTE/IUL), ambas portuguesas, totalizando dezoito instituições.

Quadro 2 - Instituições e sua localização geográfica

\begin{tabular}{l|l|l}
\hline \multicolumn{1}{c|}{ INSTITUIÇÃO } & CIDADE/ESTADO & \multicolumn{1}{c}{ REGIÃO } \\
\hline \hline Faculdade de Ciências da Saúde de Barretos (FACISB) & Barretos, SP & Sudeste \\
\hline Instituto Universitário de Lisboa (ISCTE/IUL) & Lisboa, POR & Portugal \\
\hline Universidade de Brasília (UNB) & Brasília, DF & $\begin{array}{l}\text { Centro } \\
\text { Oeste }\end{array}$ \\
\hline Universidade de Coimbra (UC) & Coimbra, POR & Portugal \\
\hline Universidade de São Paulo (USP) & São Paulo, SP & Sudeste \\
\hline Universidade do Estado de Santa Catarina (UDESC) & Florianópolis, SC & Sul \\
\hline Universidade Estadual de Londrina (UEL) & Londrina, PR & Sul \\
\hline Universidade Estadual Paulista, Júlio de Mesquita Filho (UNESP) & Marília, SP & Sudeste \\
\hline Universidade Federal de Goiás (UFG) & Goiânia, GO & Centro \\
& & Oeste \\
\hline Universidade Federal da Paraíba (UFPB) & João Pessoa, PB & Nordeste \\
\hline Universidade Federal de Minas Gerais (UFMG) & $\begin{array}{l}\text { Belo Horizonte, } \\
\text { MG }\end{array}$ & Sudeste \\
\hline Universidade Federal de Pernambuco (UFPE) & Recife, PE & Nordeste \\
\hline Universidade Federal de Santa Catarina (UFSC) & Florianópolis, SC & Sul \\
\hline Universidade Federal de São Carlos (UFSCar) & São Carlos, SP & Sudeste \\
\hline Universidade Federal do ABC (UFABC) & Santo André, SP & Sudeste \\
\hline Universidade Federal do Estado do Rio de Janeiro (UNIRIO) & Rio de Janeiro, RJ & Sudeste \\
\hline Universidade Federal do Rio de Janeiro/Instituto Brasileiro de \\
Informação em Ciência da Informação (UFRJ/IBICT) & Rio de Janeiro, RJ & Sudeste \\
\hline Universidade Federal do Rio Grande do Sul (UFRGS) & Porto Alegre, RS & Sul \\
\hline
\end{tabular}

Fonte: Os autores (2016).

Observa-se maior concentração de trabalhos sobre a temática realizados por pesquisadores de instituições do estado de São Paulo (5 ocorrências), colaborando para afirmar que a região Sudeste do Brasil mantém a dianteira nos estudos da temática, seguida pela região sul, nordeste e centro-oeste e ausência de trabalhos apresentados por 
representantes da região norte do país. Essa característica pode ser observada na figura 2, onde se vê que as arestas mais destacadas conectam instituições de São Paulo com instituições geograficamente mais próximas ou do mesmo estado (USP, UNESP e UFG).

Esta informação ajuda a entender essa região como um cluster, entretanto, nem a USP ou a UNESP, atores que mantém relações fortes, são o centro desta rede. O mais alto grau de centralidade pertence à UFABC, pois constituiu quatro ligações.

Figura 3 - Rede de colaboração entre instituições nos artigos sobre "Redes" publicados no GT7 (2011 a 2016)

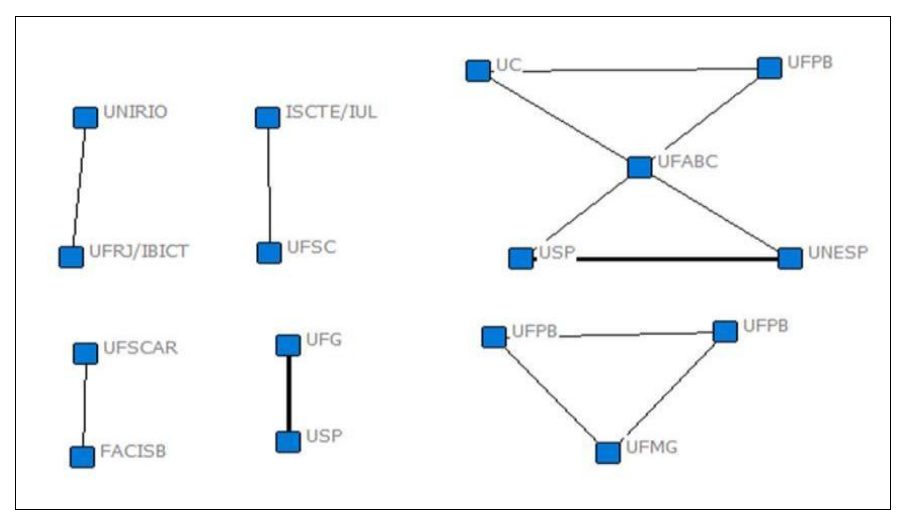

Fonte: Os autores (2016).

A figura acima mostra instituições que colaboraram com autores de outras instituições, onde é possível ver ligações levemente mais fortes entre autores da Universidade Federal de Goiás e Universidade de São Paulo, com duas publicações, bem como outro autor da Universidade de São Paulo colaborando com autor da Universidade Estadual Paulista "Júlio de Mesquita Filho", também com duas publicações. Assim, esta visualização destaca principalmente as instituições da Região Sudeste. As demais colaborações entre instituições constam de uma publicação.

Ao longo do período estudado observa-se a ampliação não só do número de trabalhos, pesquisadores, mas também de instituições representadas no estudo de "redes". Em 2011, eram cinco instituições, todas do estado de São Paulo; em 2012, foram duas instituições, uma de São Paulo e uma de Goiás; 2013, foram sete instituições, dos estados de São Paulo, Paraíba, Goiás, Minas Gerais, Brasília e Pernambuco; 2014, foram sete instituições dos estados de São Paulo, Rio Grande do Sul, Rio de Janeiro e Brasília; 2015, foram cinco instituições, dos estados do Paraná, Paraíba, Santa Catarina, São Paulo mais uma estrangeira (Lisboa, Portugal); 2016, foram quatro instituições, de Brasília, Santa Catarina, São Paulo e uma estrangeira (Lisboa, Portugal). Esses dados são relevantes para perceber como o interesse pelo tema cresceu quantitativamente no universo acadêmico brasileiro, inclusive com dispersão geográfica, ou saída do conhecido "Eixo Rio-São Paulo", e se refletiram nos trabalhos em $\mathrm{CI}$.

A conexão com pesquisadores estrangeiros demonstra o que Martinho (2003, p. 32) afirma sobre a extensão do caminho na rede: 
"Embora a proximidade espacial possa contribuir para diminuir a extensão de caminho, o 'grau de separação' não está vinculado ao território, mas à trama imaterial dos relacionamentos (que não se prende a fronteiras)."

Ao considerar relevante para a compreensão da forma como o tema "redes" perpassa o universo das pesquisas apresentadas no GT7, a ocorrência de referência a terminologia "redes", no título ou nas palavraschave, percebe-se que muitos trabalhos apresentados neste GT são sistematizados por essa área temática em pesquisas que não tem o objetivo de analisar as redes sociais enquanto assunto principal. Assim, a extração das expressões "rede" ou "redes" no título ou nas palavras-chave dos artigos passam mais segurança quanto à análise de outros assuntos afins. Para tanto, apresentamos a descrição dos assuntos principais dos artigos pesquisados, com base nas palavras-chave, para fins comparativos pois estes, eventualmente, podem ser interpretados como parte da temática das "redes".

Gráfico 4 - Assuntos mais discutidos nos artigos sobre "Redes" publicados no GT7 (2011 a 2016)

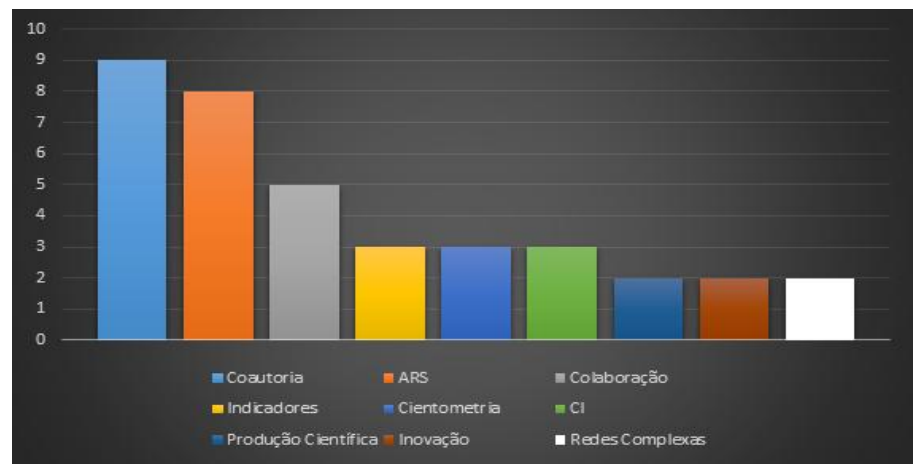

Fonte: Os autores (2016).

O levantamento apresenta um total de 78 palavras-chave e a constatação dos assuntos mais discutidos nos artigos foi possível com uma análise de conteúdo, em que se verifica algumas pequenas variações nas descrições das palavras-chave, mas sem alteração da percepção dos assuntos discutidos. Por exemplo, analisando os três assuntos mais discutidos, o assunto "Coautoria" (o mais discutido), teve outras variações como "Redes de coautoria" e "Coautorias na Fonoaudiologia". O assunto "ARS" visualizado no gráfico corresponde a Análise de Redes Sociais. Contudo, a abreviação "ARS" só foi visualizada uma única vez como palavra-chave. Nos demais artigos a preferência dos autores foi em escrever "Análise de Redes Sociais", por extenso. Ainda assim, no gráfico acima preferiu-se usar a abreviação "ARS" para melhor edição. Por fim, o terceiro assunto mais discutido, "Colaboração", também teve como variações as palavras-chave "Redes de colaboração científica", "Colaboração científica" e "Redes colaborativas". Outros assuntos não apresentados no gráfico correspondem somente a palavras-chave que foram descritas apenas uma vez pelos autores das publicações. 


\section{Considerações finais}

Considera-se o objeto principal de análise desta pesquisa uma rede de informação de caráter científico-tecnológico surgida e que evolui no âmbito das universidades brasileiras e nas comunidades de cientistas da informação e em fóruns de discussão, que tem como produto final e meio a comunicação científica em Anais, entendidos como um documento que reúne conhecimentos gerados a partir da realização de eventos de caráter científico.

Observa-se dois pontos de vista, o primeiro as "redes" consideradas como objeto de estudos dos pesquisadores em Ciência da Informação e o ponto de vista dos pesquisadores como campo de pesquisa que possibilita a sua abordagem como pertencentes a uma rede social específica ou rede sócio-técnica.

De acordo com a ARS, a rede apresenta maior qualidade de acordo com a maior quantidade de linhas ou conexões. Na medida em que no estudo de redes sociais as conexões são mais relevantes do que os atores que formam essas redes, a temática aqui abordada apresenta relevância dentro dos eventos científicos em CI no Brasil, essa observação é corroborada pela disseminação da metodologia de ARS nas publicações da área, por instituições de ensino e pesquisa de quase todas as regiões brasileira e suas conexões com instituições estrangeiras. Do mesmo modo, é pertinente a sugestão de verificar em estudos futuros como funcionam as redes e as co-autorias em áreas outras e em pesquisas de ponta.

Observa-se que a rede formada não atingiu seu limite máximo de conectividade, pois esse estágio só acontece quando todos estão conectados com todos, fenômeno que não ocorreu como se pode observar pela ocorrência de laços ausentes.

Ficou claro nesse percurso narrativo que as inúmeras camadas que formam qualquer rede social podem ser abordadas por meio da metodologia Análise de Redes Sociais (ARS) e que se pode explorar a dinâmica das redes mudando o ponto de vista ou o ponto de referência inicial, basta perspicácia, domínio teórico e clareza metodológica.

Por fim, a relevância de estudos como esse está na possibilidade da comunidade de cientista da informação, que pesquisam o tema "Redes", superar os limites de seu "horizonte crítico" (MARTINHO, 2003), ou seja, enxergar ou conhecer a extensão das redes das quais fazem parte, além dos dois níveis de conexões, e observar o que está fora do seu campo de visão.

\section{Referências}

ASSOCIAÇÃO NACIONAL DE PESQUISA E PÓS-GRADUAÇÃO EM CIÊNCIA DA INFORMAÇÃO. GT7 Produção e Comunicação da Informação em Ciência, Tecnologia \& Inovação. [200-?]. Disponível em: <http://gtancib.fci.unb.br/index.php/gt-07>. Acesso em: 7 dez. 2016. 
BALANCIERI, R. Análise de redes de pesquisa em uma plataforma de gestão em ciência e tecnologia: uma aplicação à plataforma Lattes. 2004. 117f. Dissertação (Mestrado em Engenharia de Produção de Produção) Universidade Federal de Santa Catarina, 2004. Disponível em: <https://repositorio.ufsc.br/bitstream/handle/123456789/87468/224645. pdf?sequence =1>. Acesso em: 28 dez. 2016.

BASSETTO, C. L. Redes de conhecimento: espaço de competência em informação nas organizações contemporâneas. Bauru, SP: Ide@, 2013.

ENCONTRO NACIONAL DE PESQUISA EM CIÊNCIA DA INFORMAÇÃO (ENANCIB), 12., 2011, Brasília. Anais... Brasília: Thesaurus, 2011.

ENCONTRO NACIONAL DE PESQUISA EM CIÊNCIA DA INFORMAÇÃO (ENANCIB), 13., 2012, Rio de Janeiro. Anais... Rio de Janeiro: Fiocruz, 2012. Disponível em: <http://www.enancib2012.icict.fiocruz.br/>. Acesso em: 8 dez. 2016

ENCONTRO NACIONAL DE PESQUISA EM CIÊNCIA DA INFORMAÇÃO (ENANCIB), 14., 2013, Florianópolis. Anais... Florianópolis: UFSC, 2013. Disponível em: <http://enancib.sites.ufsc.br/index.php/enancib2013/XIVenancib/schedCo nf/presentations $>$. Acesso em: 8 dez. 2016

ENCONTRO NACIONAL DE PESQUISA EM CIÊNCIA DA INFORMAÇÃO (ENANCIB), 15., 2014, Belo Horizonte. Anais... Belo Horizonte: ECI/UFMG, $2014 . \quad$ Disponível em: <http://enancib2014.eci.ufmg.br/documentos/anais/anaisgt7/view.>Acesso em: 8 dez. 2016.

ENCONTRO NACIONAL DE PESQUISA EM CIÊNCIA DA INFORMAÇÃO (ENANCIB), 16., 2015, João Pessoa. Anais... João Pessoa: UFPB, 2015. Disponível em: <http://www.ufpb.br/evento/lti/ocs/index.php/enancib2015/enancib2015/ schedConf/presentations. > Acesso em: 8 dez. 2016.

ENCONTRO NACIONAL DE PESQUISA EM CIÊNCIA DA INFORMAÇÃO (ENANCIB), 17., 2016, Salvador. Anais... Salvador: UFBA, 2016. Disponível em: <http://www.ufpb.br/evento/lti/ocs/index.php/enancib2016/enancib2016/ schedConf/presentations>. Acesso em: 8 dez. 2016.

HAGSTROM, Warren O. The scientific community. New York: Basic Books, 1965.

LARA, M. L. G.; LIMA, V. M. A. Termos e conceitos sobre redes sociais colaborativas. In: POBLACIÓN, D. A. ; MUGNAINI, R.; RAMOS, L. M. S. V. C. (Orgs.). Redes sociais e colaborativas em informação científica. São Paulo: Angellara, 2009. p. 605-637.

MARTELETO, R. M. Análise das redes sociais: aplicação nos estudos de transferência da informação. Ciência da Informação, Brasília, v. 30, n. 1, p. 71-81, jan./abr. 2001. 
MARTELETO, R. M.; TOMAÉL, M. I. A metodologia de análise de Redes sociais. In: VALENTIM, M. L. P. Métodos qualitativos de pesquisa em Ciência da Informação. São Paulo: Polis, 2005. p. 81-100.

MARTINHO, C. Redes: uma introdução às dinâmicas da conectividade e da auto-organização. Brasília: WWF-Brasil, 2003.

PINTO, A. L. et al. Visualização da informação das redes sociais através de programas de cienciografia. In: POBLACIÓN, D. A.; MUGNAINI, R.; RAMOS, L. M. S. V. C. (Orgs.). Redes sociais e colaborativas em informação científica. São Paulo: Angellara, 2009. p. 289-312.

SILVA, A. K. A. da et al. Redes intraorganizacionais e interorganizacionais: da teoria das redes às tecnologias de informação e comunicação. In: DUARTE, E. N.; LLARENA, R. A. da S.; LIRA, S. de L. (Orgs.). Da informação à auditoria de conhecimento: a base para a inteligência organizacional. João Pessoa: Editora UFPB, 2014. p. 205-236.

SILVA, A. K. A. da. A dinâmica das redes sociais e as redes de coautoria. Perspectivas em Gestão \& Conhecimento, João Pessoa, v. 4, n. esp., p. 27-47, out. 2014. Disponível em: <http://periodicos.ufpb.br/ojs2/index.php/pgc>. Acesso em: $13 \mathrm{dez}$. 2016.

SILVA, A. B. de O. et al. Estudo da rede de coautoria e da interdisciplinaridade na produção científica com base nos métodos de análise de redes sociais: avaliação do caso do programa de pós-graduação em ciência da informação-PPGCI?UFMG. Encontros Bibli, n. esp., p. 179194, 2006.2 Disponível em: <https://periodicos.ufsc.br/index.php/eb/article/view/15182924.2006v11nesp1p179/422>. Acesso em: 20 dez. 2016. 